\title{
Aptamer-based methods for biosensing of estrogen receptors and human epidermal growth factor receptor 2 in breast cancer
}

\author{
Rajesh Ahirwar ${ }^{1}$, Saroj Kumar², and Kamini Arya ${ }^{1}$ \\ ${ }^{1}$ National Institute for Research in Environmental Health \\ ${ }^{2}$ Apeejay Stya University
}

October 17, 2020

\begin{abstract}
Breast cancer is a common malignancy and a leading cause of cancer related mortality among women. Early diagnosis and better prognosis are vital to improve breast cancer outcomes and survival rates. Clinical assessment of the expression levels of biomarkers including estrogen receptors (ERs) and human epidermal growth factor receptor 2 (HER2) had been beneficial in assisting the prognosis and deriving treatment regimes. Conventionally, these biomarkers were detected mostly using antibodybased methods. However, recent advances in identifying aptamers as antibody substitutes have favoured development of aptamer-based sensing platforms for rapid, cost-effective, and point-of-care testing applications. The last decade witnessed substantial use of aptamers in cancer diagnosis. This review provides a thorough update of recent developments in aptamerbased detection of human estrogen receptors (ERs) and epidermal growth factor receptor 2 (HER2) in breast cancer. The widely used tissue and serum-based biomarkers of breast cancer are introduced, and the conventional methods of ERs and HER2 detection are discussed. Electrochemical and optical methods of aptasensing strategies based on "on/off", "target sandwich", "nanomaterial beacons" and AuNP-based localized surface plasmon resonance (LSPR) approaches are then elaborated. Finally, a perspective for futuristic remote health care monitoring of breast cancer patients using smart wireless nano-aptasensor is provided.
\end{abstract}

\section{Hosted file}

Manuscript.pdf available at https://authorea.com/users/367942/articles/487212-aptamer-basedmethods-for-biosensing-of-estrogen-receptors-and-human-epidermal-growth-factor-receptor2-in-breast-cancer 

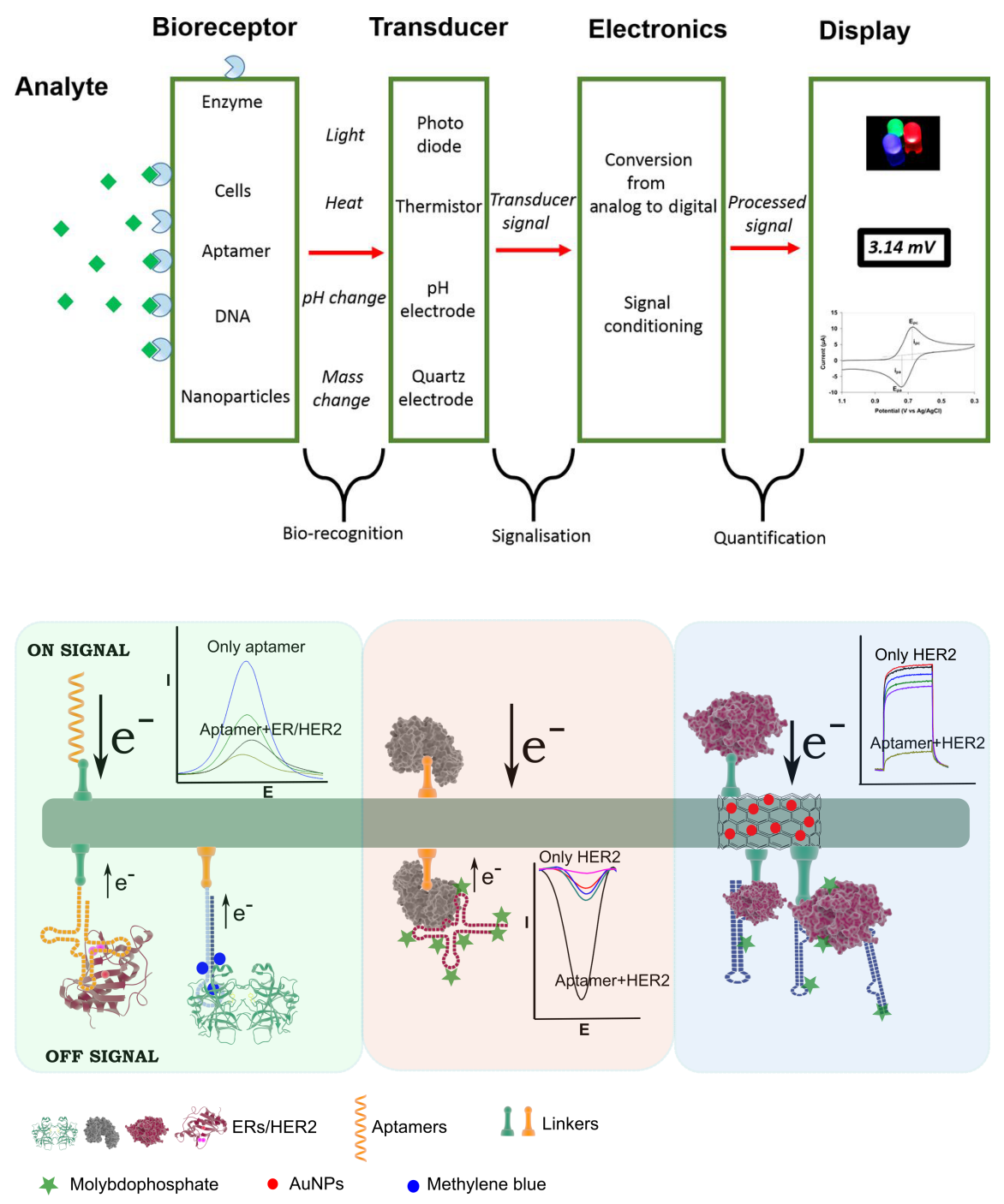


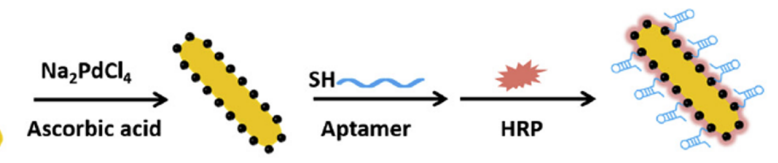

Gold nanorod

GNR@Pd SS

GNR@Pd SSs-Apt-HRP

(GNR)
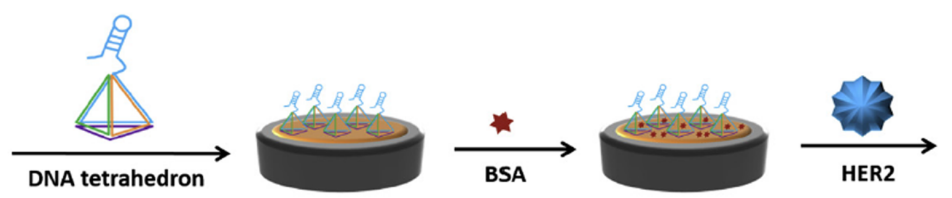

Gold electrode
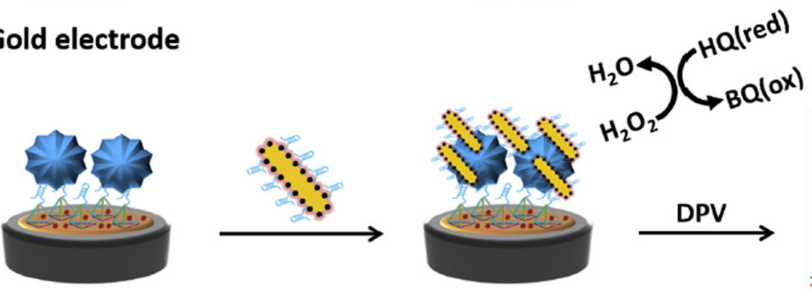

$\mathrm{H}_{2} \mathrm{O}_{2}$

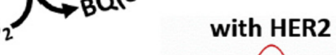

HRP (horseradish peroxidase)

- BSA (bull serum albumin)

HER2 (human epidermal growth factor receptor 2 )
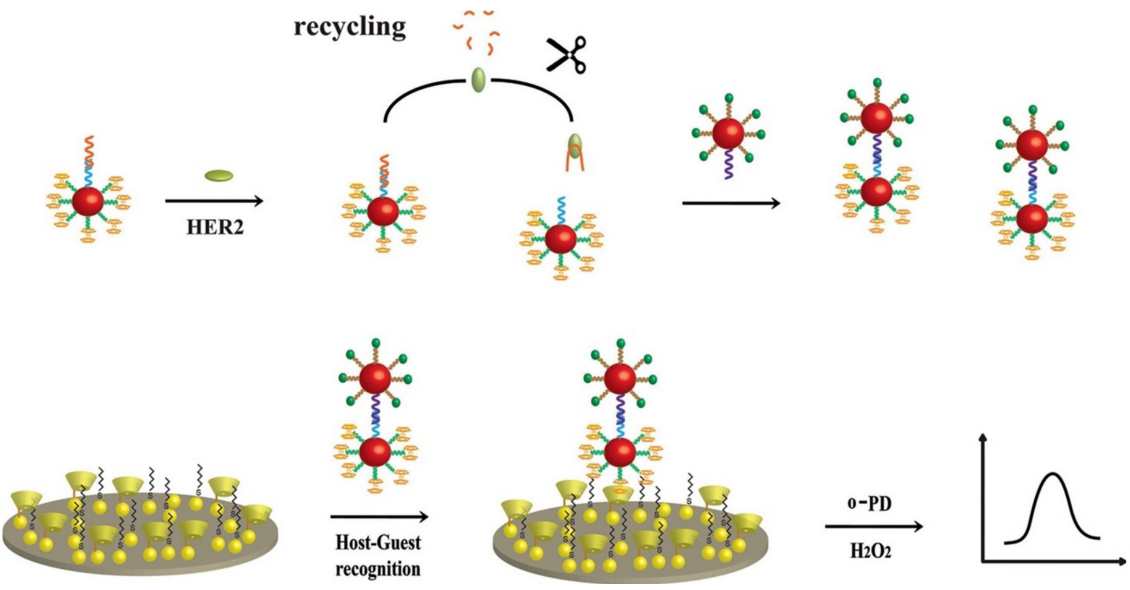
(1)

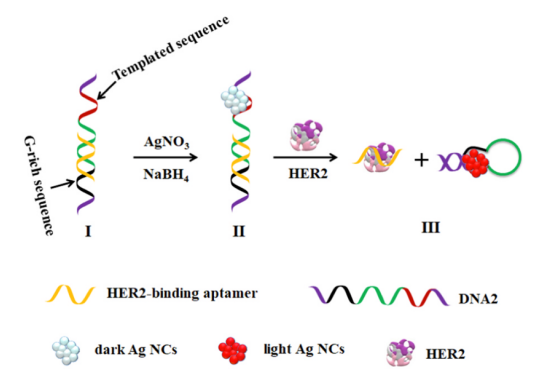

(3)
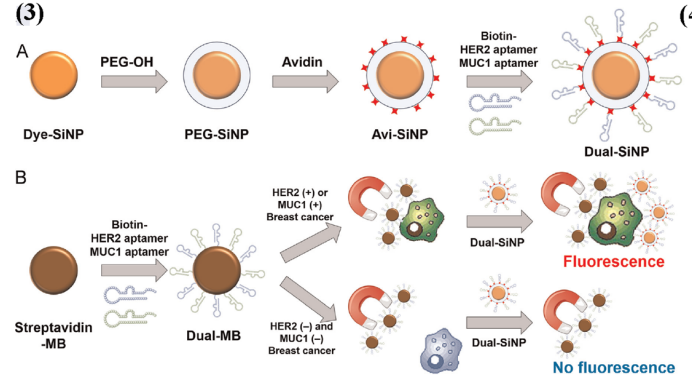

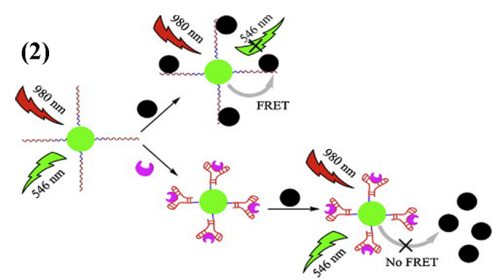

UCPs

- CNPs

(4)

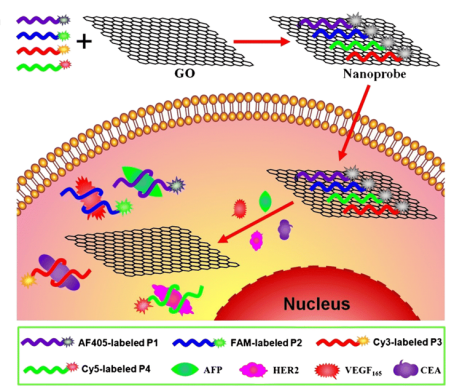

A

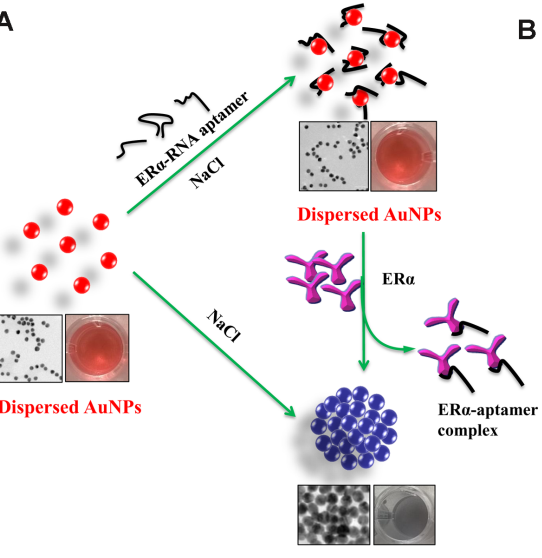

Aggregated AuNPs

B

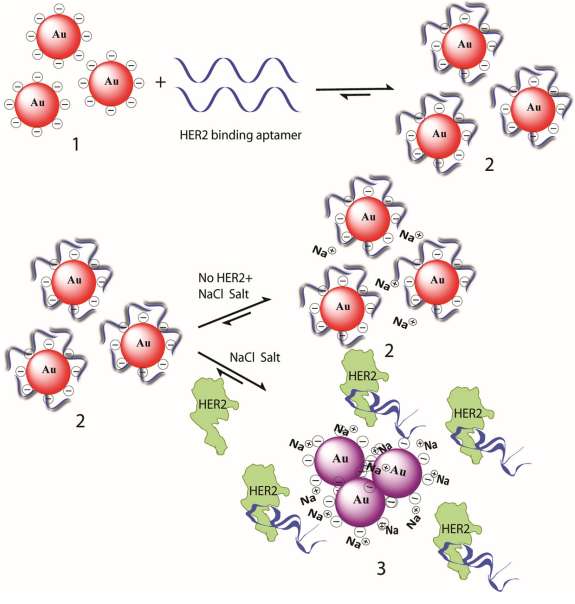

